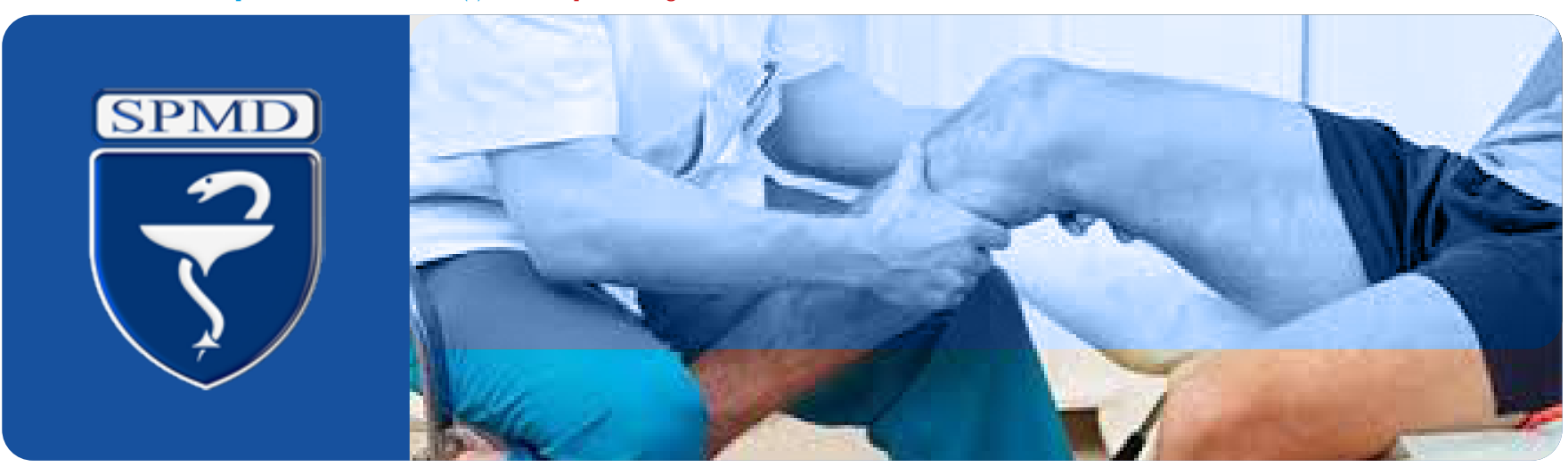

\title{
Exercício no Frio
}

Dr. Marcos Miranda

Especialista em Medicina Desportiva e Competência em Medicina Hiperbárica e Subaquática e Competência em Medicina Aeronáutica; Autoridade Nacional da Aviação Civil; Centro de Medicina Desportiva de Lisboa; Secretário-geral da SPMD. Lisboa

RESUMO / ABSTRACT

A exposição a temperaturas baixas condiciona adaptações de modo a manter a homeostasia térmica, mas os mecanismos adaptativos a longo prazo são essencialmente de natureza comportamental. Descrevem- se as principais situações patológicas relacionadas com a exposição não protegida ao frio.

Exposure to low atmospheric temperatures generates adaptation responses in order to preserve body temperature within physiological limits, but long-term adaptation is essentially behavioral. The main medical conditions related to non-protected cold exposure are also briefly described.

PALAVRAS-CHAVE / KEYWORDS

Frio, exercício, hipotermia, geladuras

Cold, exercise, hypothermia, frostbite

A exposição a ambientes térmicos extremos desencadeia adaptações fisiológicas agudas e crónicas de modo a manter a homeostasia. No entanto, quando a essa exposição se associam outras variáveis ambientais, essas mesmas adaptações podem originar manifestações fisiopatológicas, por vezes com consequências fatais. O ser humano consegue viver em ambientes de frio extremo, mas a maior parte das adaptações a este ambiente são de natureza comportamental.

Habitualmente associamos a ocorrência de patologia ou lesões induzidas pela exposição a baixas temperaturas com os desportos de inverno (esqui, patinagem no gelo, trenó/bobsleigh ou alpinismo), mas também podem ocorrer em desportos náuticos (vela, kayak, motonáutica, esqui aquático, surf), aquáticos (natação em águas abertas) ou subaquáticos. A prática recente de atividades designadas como mais radicais, como os trails de montanha ou nos polos, vieram aumentar o número de potenciais praticantes em risco. Outras populações em risco são constituídas por militares, cientistas, turistas e ainda múltiplos profissionais que atuam em ambientes inóspitos e gélidos.

A transferência térmica entre o corpo humano e o ambiente que o rodeia é descrita por vários mecanismos físicos tendentes ao equilíbrio de temperatura entre os vários ambientes, habitualmente por transferência de calor do mais "quente" para o mais "frio", seja por contacto direto, irradiação infravermelha, movimento de massas fluidas (convecção) e ainda, no caso humano, pela sudorese. Deste modo, e a título de exemplo paradoxal, em situação de temperatura ambiente negativa, mas com um dia de sol refletido na superfície da neve, a temperatura corporal pode aumentar por efeito da irradiação do solo para o corpo.

A manutenção da temperatura necessária ao funcionamento corporal em ambiente frio é assegurada pela deteção da diminuição e pelo desencadear de reações tendentes a reduzir a sua perda e ainda a aumentar a produção de calor.

Os sensores térmicos periféricos são ativados essencialmente pela variação térmica e possuem uma ligação estreita com as vias da dor para extremos de temperatura. Os sensores centrais, no centro termorregulador do hipotálamo, são ativados pelas variações da temperatura central. As vias térmicas são independentes, mas existe integração ao nível cortical, desencadeando sobretudo alterações comportamentais, respostas autonómicas vasculares e metabólicas ao nível do tronco cerebral e ainda reflexos posturais ao nível dos núcleos da base. Estão descritas igualmente respostas locais, periféricas (vasculares - cutâneas - e metabólicas - tecido adiposo castanho) através dos receptores alfa-2 adrenérgicos.

A conservação e produção de calor são feitas essencialmente à custa da ineficiência da contração muscular, cujo consumo energético é convertido apenas em cerca de $20-25 \%$ em energia mecânica e o restante dissipado sob a forma de energia térmica (ativação das fibras musculares através dos recetores beta-adrenérgicos), do aumento do metabolismo basal (T4), da insulação cutânea e da hemoconcentração, mecanismo este que leva à perda de água por aumento dos fluidos extravasculares e da produção de urina.

A exposição a baixas temperaturas, sem que os mecanismos de adaptação consigam manter a temperatura central acima dos $35^{\circ} \mathrm{C}$, ou seja uma situação em que o atleta está a perder calor mais 
rapidamente do que consegue produzir, origina um quadro patológico de hipotermia (quando a temperatura baixa dos $30^{\circ} \mathrm{C}$, cessa qualquer resposta adaptativa e o organismo tende a equilibrar com a temperatura ambiente); em conjugação com outros efeitos ambientais, como a água ou o vento, e mantendo a temperatura central, as lesões são essencialmente tecidulares.

A hipotermia pode ser classificada como aguda, subaguda e subcrónica.

A hipotermia aguda, de imersão (parcial/total) ou submersão, ocorre habitualmente pela imersão súbita em água fria e desencadeia aquilo que se designa como a Resposta de Choque ao Frio e que se caracteriza por um descontrolo respiratório (gasp) e por hiperventilação, que desencadeia alcalose respiratória, com redução da perfusão cerebral e consequente perturbação cognitiva, muitas vezes associado a pânico, permite a passagem de água para as vias aéreas e leva ao afogamento. Por outro lado, a vasoconstrição súbita e generalizada, com um brusco aumento do débito central e taquicardia, pode levar à falência e paragem cardíaca. Se esta situação conseguiu ser ultrapassada, mas a permanência dentro de água se mantém, vai instalar-se a Incapacitação Pelo Frio, com perturbação cognitiva e perda do controlo motor, inibindo a possibilidade de continuar a tentar resolver a situação ou manter atividade geradora de calor. Esta situação resulta da diminuição de aporte sanguíneo aos músculos periféricos, afetando a sua capacidade funcional, o que vai evoluir irreversivelmente para a hipotermia. A submersão tem sido habitualmente relacionada com crianças e exposição a água gelada.

Em circunstâncias de adaptação ao frio, a vasoconstrição, sobretudo das extremidades, é modulada por períodos transientes de vasodilatação, mediada a nível neurológico central, com o objetivo de proteger os tecidos e manter a destreza nos dedos. Esta resposta está aumentada se as mãos forem frequentemente expostas ao frio com manutenção da temperatura central e cutânea e inibida em algumas patologias (Diabetes Mellitus, por exemplo), potenciando o risco de lesão tecidular. Por outro lado, as reações da Resposta de Choque ao Frio diminuem com a exposição repetida à imersão.

A hipotermia subaguda está habitualmente associada à exposição ao ar frio com vento e chuva, durante horas ou dias. Este tipo de exposição gera igualmente fenómenos de habituação, com menor perceção de desconforto pelo frio e redução das respostas termogénicas musculares. A hipotermia subcrónica ocorre habitualmente em militares envolvidos em operações longas (dias/ semanas) ou em ambiente urbano, em idosos malnutridos, expostos a baixas temperaturas.

À hipotermia associa-se o risco de desidratação potenciado pelos mecanismos de adaptação, nomeadamente a hiperventilação, hemoconcentração, débito urinário aumentado, sudorese por vestuário desadequado, diminuição do estímulo da sede e redução voluntária da ingestão de líquidos para evitar diurese frequente.

A cascata semiológica da hipotermia evolui pelos primeiros sinais de alarme, que são o tremor muscular involuntário, seguindo-se a incapacidade funcional, a depressão neuro- cognitiva e culminando em eventos disrítmicos cardíacos

\section{As lesões tecidulares são de dois tipos:}

As Lesões Não-Congelantes (Pé de Trincheira e Pé de Imersão) derivam do contacto prolongado da pele das extremidades com um ambiente frio e húmido $\left(0-15^{\circ} \mathrm{C}\right)$, desencadeando lesão neurovascular com lesão tecidular que poderá evoluir para a gangrena

As geluras (ou geladuras) assumem um quadro de verdadeiras queimaduras pelo frio, causadas pela vasoconstrição extrema e formação de cristais de gelo ou mesmo congelamento dos tecidos. Classificam-se em 4 graus consoante a profundidade da lesão e leva muitas vezes à perda total das partes afetadas. A gravidade destas lesões resulta da interação de vários fatores ambientais (temperatura de exposição, efeito da velocidade do vento na temperatura - wind chill factor (Figura), tempo de exposição) e individuais (genética, equipamentos de proteção, fármacos, co-morbilidades - diabetes, episódios anteriores...).

A prevenção das lesões induzidas pelo frio passa pelo uso de vestuário adequado, em camadas, que são removidas em função dos níveis de atividade física, de modo a minimizar a acumulação de suor e manter a sensação de conforto térmico, mudas frequentes para roupa seca, luvas isolantes e luvas interiores de proteção contra queimaduras de contacto ou exposição momentânea a temperaturas extremamente baixas, meias secas e mudadas frequentemente, vigilância das extremidades e áreas de pele expostas, não usar cremes "hidratantes" ou de proteção (exceto nos lábios) devido à falsa sensação de segurança motivada por um aumento da percepção de calor (facial). Deve ser evitado o tabagismo e ter especial atenção a co-morbilidades que interfiram na resposta autonómica e vascular (aterosclerose, diabetes, fármacos vasoconstritores) e ainda o uso de vestuário demasiado justo.

A terapêutica no terreno das situações menos graves de hipotermia passa em primeiro lugar pela proteção e redução de mais perdas de calor (tapar a cabeça, que não tem vasoconstrição e por isso é um local importante de perda de calor) e permitir o reaquecimento natural. Deve-se evitar a utilização de fontes diretas de calor, pelo risco de lesar tecidos com a sensibilidade alterada, e bebidas alcoólicas, pelo seu efeito vasodilatador cutâneo. Caso a vítima esteja consciente, poderão ser administradas bebidas mornas, pelo seu efeito reconfortante e ainda para reforçar a hidratação, diminuindo o risco de tromboembolismo devido à hemoconcentração.

As geluras de $1^{\circ}$ grau e, eventualmente algumas de $2^{\circ}$ grau, podem recuperar espontaneamente e ser tratadas localmente. As de grau mais avançado devem receber tratamento hospitalar e devem ser envidados todos os esforços no sentido de evitar o descongelamento das lesões ou, caso não seja possível, assegurar que não ocorre recongelamento, pela gravidade exponencial do dano final. 
A exposição simultânea ao frio em ambiente hipóxico (montanha) pode potenciar a ocorrência de situações de hipotermia. A performance física está diminuída, quer para esforços máximos, quer para esforços de longa duração, o que vai perturbar as atitudes comportamentais e fisiológicas de adaptação ao frio. O tempo de exercício até atingir o ponto de exaustão está francamente diminuído. A diminuição da $\mathrm{PaO}_{2}$ origina que o SNC diminua o número de unidades motoras recrutadas nos músculos periféricos, mas não nos músculos respiratórios, uma vez que o fornecimento cerebral de $\mathrm{O}_{2}$ é prioritário, e para assegurar que o exercício termina antes que ocorra uma falha crítica - anoxia. Um outro fator que poderá condicionar esta diminuição da performance muscular é o balanço energético negativo devido a vários fatores voluntários e involuntários (diminuição do apetite em alta montanha, diurese, mal de montanha, aumento do metabolismo basal, tempo de atividade aumentado) que vão condicionar a redução dos depósitos de glicogénio muscular. Esta redução é igualmente potenciada pelo aumento do seu consumo para esforços de menor intensidade. $\mathrm{O}$ uso de acetazolamida, a menor qualidade do sono e outros fatores neuropsicológicos são outros fatores que diminuem a performance física. Têm sido descritos fenómenos de adaptação cruzada entre a aclimatação ao calor e à altitude (hipoxia) através da maior expressão das proteínas de choque térmico, nomeadamente a HSP90. Estes estudos sugerem que o treino no calor pode aumentar a tolerância à hipoxia, diminuindo os seus efeitos em altitude e permitindo minorar as consequências desta interação frio-hipoxia.

As expedições polares e turísticas na Antártica estão sujeitas a um stress térmico moderadamente hipóxico, pois ao contrário da calote polar do Ártico, que é constituída por água congelada e ao nível do mar, o planalto Antártico eleva-se acima dos $2800 \mathrm{~m}$, o que explica a diferença térmica de $-40^{\circ} \mathrm{C}$ em relação ao Polo Norte. Também foi descrita uma elevada expressão de proteínas de choque térmico (HSP65) em indivíduos sujeitos a exposição crónica ao frio neste continente.

A ocorrência de hipotermia em ambiente hiperbárico subaquático concorre igualmente para o agravamento de manifestações fisiopatológicas que poderão advir desta prática, sobretudo em caso de utilização de mistura respiratória em escafandro autónomo ("SCUBA" ou mergulho com garrafa). De facto, a imersão subaquática, per se, origina um aumento da pressão nos membros inferiores com mobilização de cerca de $700 \mathrm{ml}$ de sangue do compartimento venoso, o que vai desencadear uma reação para contrariar (ou compensar) este aparente aumento da volemia - aumento da diurese e extravasão de fluidos para o compartimento extravascular. Esta reação, conducente à desidratação, é cumulativa com as adaptações à diminuição da temperatura central. A inalação de uma mistura gasosa seca e fria contribui ainda mais para a desidratação e hipotermia. 0

Efeito de resfriamento (do vento na temperatura - "windchill factor")

\begin{tabular}{|c|c|c|c|c|c|c|c|c|c|c|c|c|c|}
\hline \multicolumn{14}{|c|}{ Efeito de resfriamento (do vento na temperatura - "windchill factor") } \\
\hline & $10^{\circ} \mathrm{C}$ & $5^{\circ} \mathrm{C}$ & $0^{\circ} \mathrm{C}$ & $-5{ }^{\circ} \mathrm{C}$ & $-10^{\circ} \mathrm{C}$ & $-15^{\circ} \mathrm{C}$ & $-20^{\circ} \mathrm{C}$ & $-25^{\circ} \mathrm{C}$ & $-30^{\circ} \mathrm{C}$ & $-35^{\circ} \mathrm{C}$ & $-40^{\circ} \mathrm{C}$ & $-45^{\circ} \mathrm{C}$ & $-50^{\circ} \mathrm{C}$ \\
\hline $10 \mathrm{~km} / \mathrm{h}$ & 8,6 & 2,7 & $-3,3$ & $-9,3$ & $-15,3$ & $-21,1$ & $-27,2$ & $-33,2$ & -39.2 & $-45,1$ & $-51,1$ & $-57,1$ & 63 \\
\hline $15 \mathrm{~km} / \mathrm{h}$ & 7,9 & 1,7 & $-4,4$ & $-10,6$ & $-16,7$ & $-22,9$ & $-29,1$ & $-35,2$ & $-41,4$ & $-47,6$ & $-51,1$ & .59 .9 & -88.1 \\
\hline $20 \mathrm{~km} / \mathrm{h}$ & 7,4 & 1,1 & $-5,2$ & $-11,6$ & $-17,9$ & $-24,2$ & $-30,5$ & $-36,8$ & $-43,1$ & $-49,4$ & $-55,7$ & -62 & $-69,3$ \\
\hline $25 \mathrm{~km} / \mathrm{h}$ & 6,9 & 0,5 & $-5,9$ & $-12,3$ & $-18,8$ & $-25,2$ & $-31,6$ & -38 & $.44,5$ & $-50,9$ & $-57,3$ & 63.7 & 70,2 \\
\hline $30 \mathrm{~km} / \mathrm{h}$ & 6,6 & 0,1 & $-6,5$ & -13 & $-19,5$ & -26 & $-32,6$ & $-39,1$ & $-45,6$ & $-52,1$ & .58 .7 & .65 .2 & .71 .7 \\
\hline $35 \mathrm{~km} / \mathrm{h}$ & 6,3 & $-0,4$ & -7 & $-13,6$ & $-20,2$ & $-26,8$ & $-33,4$ & -40 & $-46,6$ & $-53,2$ & $-59,8$ & 68,4 & $-73,1$ \\
\hline $40 \mathrm{~km} / \mathrm{h}$ & 6 & $-0,7$ & $-7,4$ & $-14,1$ & $-20,8$ & $-27,4$ & $-34,1$ & $-40,8$ & $-47,5$ & $.54,2$ & $-60,9$ & .676 & $.74,2$ \\
\hline $45 \mathrm{~km} / \mathrm{h}$ & 5,7 & -1 & $-7,8$ & $-14,5$ & $-21,3$ & -28 & $-34,8$ & $-41,5$ & $-48,3$ & $-55,1$ & 61,8 & 68.6 & .75 .3 \\
\hline $50 \mathrm{~km} / \mathrm{h}$ & 5,5 & $-1,3$ & $-8,1$ & -15 & $-21,8$ & $-28,6$ & $-35,4$ & $-42,2$ & -49 & $-55,8$ & -62.7 & .695 & $.76,3$ \\
\hline $55 \mathrm{~km} / \mathrm{h}$ & 5,3 & $-1,6$ & $-8,5$ & $-15,3$ & $-22,2$ & $-29,1$ & -38 & $-42,8$ & $-49,7$ & $-56,6$ & $-63,4$ & 70.3 & .77 .2 \\
\hline $60 \mathrm{~km} / \mathrm{h}$ & 5,1 & $-1,8$ & $-8,8$ & $-15,7$ & $-22,6$ & $-29,5$ & $-36,5$ & $-43,4$ & $.50,3$ & $-57,2$ & $-64,2$ & .711 & .78 \\
\hline \multicolumn{6}{|c|}{$\begin{array}{l}\text { Perigo reduzido para menos de } 1 \mathrm{~h} \\
\text { de exposição da pele seca } \\
\text { Perigo máximo de falsa sensação de } \\
\text { segurança }\end{array}$} & \multicolumn{5}{|c|}{$\begin{array}{l}\text { Perigo - Pele exposta congela em } 1 \\
\text { minuto }\end{array}$} & \multicolumn{3}{|c|}{$\begin{array}{l}\text { Perigo grande - Pele } \\
\text { pode congelar em } 30 \text { s }\end{array}$} \\
\hline
\end{tabular}

Figura 1 - Windchill factor

exercício, em ambiente de mergulho com garrafa, está contraindicado, pois é um fator que pode induzir a ocorrência de doença de descompressão (DCI). A desidratação e a hipotermia são outros fatores que propiciam a DCI. Estamos assim perante uma interação complexa entre mecanismos adaptativos que podem condicionar uma situação de risco lesional grave, com hipotermia e DCI. As perturbações cognitivas causadas pela baixa da temperatura central e a relativa urgência em regressar à superfície podem condicionar uma subida sem respeito pelos patamares de descompressão. A prevenção da hipotermia em ambiente subaquático hiperbárico reside na correta escolha da espessura do fato de neoprene (o isolamento térmico é conseguido pela imobilização da água nas bolhas da espuma do material, mas que é esmagado pelo aumento da pressão ambiente, tornando-se muito fino e perdendo as suas propriedades insulativas) ou na eventual utilização de fato seco (impermeável), que permite a utilização de vestuário interior mais quente e na escolha de tempos de imersão ou profundidades que minimizem a necessidade de efetuar paragens de descompressão ou ainda na interrupção do mergulho ao primeiro sinal de desconforto térmico. Na superfície deve ser aplicada proteção térmica para permitir o reaquecimento e ainda proceder-se a reforço hídrico, aquecido, se possível.

Direta ou indiretamente relacionadas com a exposição às baixas temperaturas e ar frio, estão descritas manifestações ou exacerbações de patologia do aparelho respiratório devido ao aumento da híper-reatividade brônquica, alterações cutâneas do tipo urticariforme e ainda o aumento do tempo de coagulação por interferência com todos os mecanismos da coagulação, aumentando o risco hemorrágico, e a ter em especial atenção no caso de lesões congeladas das extremidades, pois o mecanismo é reversível com o reaquecimento. As consequências sobre o aparelho cardiovascular, de novo ou agravando patologia pré-existente já foram abordadas e resultam dos mecanismos de adaptação ao frio. 
Em conclusão, a aclimatação às temperaturas ambientes baixas é modesta, e o termo mais correto deverá ser habituação (à sensação de frio). As adaptações mais relevantes são a diminuição da temperatura cutânea, mantendo a temperatura central dentro dos valores normais, e a diminuição da reação de choque ao frio. Alguns indivíduos desenvolvem uma aclimatação insulativa, em que conseguem um tempo de resposta da vasoconstrição cutânea mais rápido. A prevenção de lesões e da hipotermia passa pela manutenção e utilização de equipamento protetor adequado e seco. Situações graves de patologia induzida pelo frio devem receber tratamento hospitalar pelo seu risco de complicações secundárias ao reaquecimento.

\section{Bibliografia}

1. Auerbach, P. S. (2012). Wilderness medicine. Philadelphia, USA: Mosby Elsevier.

2. Bove, A. A., Davis, J. C. (Eds.). (2004). Bove and Davis' diving medicine. Saunders.

3. Burtscher, M., Gatterer, H., Burtscher, J., \& Mairbäurl, H. (2018). Extreme terrestrial environments: Life in thermal stress and hypoxia. A narrative review. Frontiers in physiology, 9, 572.

4. Castellani, J. W., \& Young, A. J. (2016). Human physiological responses to cold exposure: Acute responses and acclimatization to prolonged exposure. Autonomic Neuroscience, 196, 63-74.

5. Edmonds, C., Bennett, M., Lippmann, J., \& Mitchell, S. (Eds.) (2015). Diving and subaquatic medicine. CRC Press.

6. Hebestreit, H., \& Bar-Or, O. (Eds.). (2008). The young athlete. Blackwell Pub.

7. Koenig, K. L., \& Schultz, C. H. (Eds.). (2010). Koenig and Schultz's disaster medicine: comprehensive principles and practices. Cambridge University Press.

8. Kraemer, W. J., \& Rogol, A. D. (Eds.). (2005). The endocrine system in sports and exercise. Blackwell Pub.

9. McMahon, P. J. (2007). Current diagnosis and treatment in sports medicine. McGraw Hill Professional

10. Med, T. (2010). Altitude acclimatization and illness management. U.S. Army Technical Bulletin 505.

11. Med, T. (2005). Prevention and management of cold-weather injuries. U.S. Army Technical Bulletin 508

12. Navy, U. S. (2008). US Navy Diving Manual, Reu 6. Washington, DC: Department of the Navy.

13. O'Connor, F. G., Scheuring, R. A., \& Deuster, P. (2019). Environmental extremes: heat and cold. In O'Connor, F. G., Schoomaker, E. B., \& Smith, D. C. (Eds.) Fundamentals of Military Medicine. Army Medical Department - The Borden Institute.

14. Osczevski, R., \& Bluestein, M. The new wind chill equivalent temperature chart. Bulletin of the American Meteorological Society, 2005; 86(10):1453-1458.

15. Salgado, R. M., White, A. C., Schneider, S. M. \& Mermier, C. M. (2014). A novel mechanism for cross-adaptation between heat and altitude acclimation: The role of heat shock protein 90 .

16. Schwellnus, M. P. (Ed.). The Olympic textbook of medicine in sport. 2009; Vol. 14. John Wiley \& Sons.

17. Udaya, I. B., Laxmi, C. C., Kavitha, A. K., Satyaprabha, T. N., Raju, T. R., \& Patil, S. Heat shock protein response to chronic cold exposure in antarctic expedition members. International Journal of Scientific and Research Publications, 29.

18. West, J., Schoene, R., Luks, A., \& Milledge, J. (Eds.) (2012). High altitude medicine and physiology $5^{\text {th }} \mathrm{Ed}$. CRC Press.

19. Zuckerman, J. N. (Ed.). Principles and practice of travel medicine. 2013; Wiley-Blackwell.

\section{Aspetos práticos da antidopagem 2020-2021}

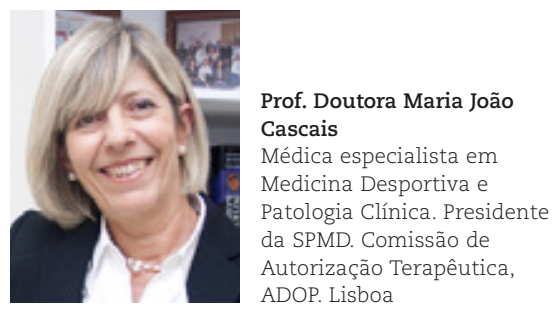

Todos os anos, os médicos, os atletas e outros agentes desportivos são confrontados com a existência de uma nova Lista de Substâncias e Métodos Proibidos emitida pela Agência Mundial Antidopagem (AMA), a partir de Janeiro do novo ano, neste caso 2021, e em adenda com a Lista de Monitorização do mesmo organismo. Este emite ainda um resumo das principais alterações feitas à lista do ano anterior para que a consulta seja mais fácil.

Estes documentos, devidamente traduzidos, são publicados no site da ADoP (Autoridade Antidopagem de Portugal) e numa Portaria publicada em Diário de República para que estejam de acordo com a legislação do País.

Indicam-se algumas alterações para o ano de 2021:

- Na lista de alterações, cuja consulta aos parceiros não está ainda concluída, prevê-se uma alteração ao regime de autorização de utilização dos medicamentos beta-2 agonistas e glucocorticoides e uma clarificação sobre drogas de abuso;

- O vilanterol poderá ser permitido numa dose máxima de 25microgramas por 24 horas, evitando assim os pedidos de Autorização Terapêutica que obrigam a vários relatórios por médico especialista;

- Em relação aos glucocorticoides, está em discussão se todas as vias injetáveis serão proibidas em 2021 ou só em 2022:

- O artigo 4.2.3 do Código Mundial Antidopagem define como "Substâncias de abuso" as "Substâncias proibidas especificamente identificadas como Substâncias de Abuso na Lista, por serem frequentemente utilizadas de forma abusiva na sociedade, fora do contexto desportivo". Como exemplo temos a cocaína, a metilenodioximetanfetamina (MDMA) e o tetrahidrocanabinol (THC);

- As hormonas e os moduladores metabólicos, atualmente com duas subclasses, foram agrupados apenas numa, já que possuem mecanismos metabólicos comuns.

No contexto da Lista atual, que vigora atá 31 de Dezembro de 2020, chama-se a atenção para uma estrutura da AMA (Autoridade Mundial Antidopagem), o sistema ADAMS (Anti-Doping Administration \& Management System), o qual, em resumo, trata da administração de todos os assuntos referentes aos atletas com número de identificação própria e gere as Autorizações Terapêuticas (AUT), que têm de estar introduzidas no sistema, a informação sobre a localização dos atletas, os resultados laboratoriais, a planificação dos controlos de dopagem e o Passaporte Biológico. Estas informações estão disponíveis para todo o mundo e têm níveis de acessibilidade de acordo com códigos, muito definidos de acordo com o utilizador.

\section{A Autorização de Utilização Terapêutica (AUT)}

$\mathrm{O}$ atleta tem o direito de ser tratado com medicamentos que constam da Lista de substâncias dopantes desde que se justifique, alguns procedimentos sejam executados e apenas após a autorização dada pela 
Comissão de Autorização Terapêutica (CAUT) da ADoP, a qual decidirá com base na AUT que o atleta deve submeter.

A ADoP está creditada pela AMA para a atribuição das AUTs e cumpre com as normas internacionais sobre esta matéria, as quais podem ser consultadas no site da ADoP: (http:// adop.pt/espad/autorizacao-terapeutica/documentos_ama.aspx)

A resposta ao pedido pode demorar até 21 dias após a receção do pedido de AUT, mas, em geral, a resposta é dada no prazo de 24 a 72 horas, dependendo, entre outros fatores, se as AUTs estão de acordo com critérios da AMA e se todos os documentos foram rececionados, nomeadamente, relatório clínico e cópias de relatórios de exames entretanto efetuados pelo atleta. Se o pedido da AUT não satisfaz os critérios da AMA leva mais tempo a ser autorizado, ou pode mesmo ser rejeitado, o que é raro acontecer no nosso País. A informação enviada pelos atletas / médicos é colocada na plataforma informática ADAMS e pode ser visualizada pelos órgãos competentes do Comité Olímpico Internacional, Federações Internacionais, AMA e outras CAUTs internacionais, sempre que exista dúvida médica ou resultado laboratorial por esclarecer, por exemplo. Esta visibilidade obriga à excelência da CAUT portuguesa, no sentido de se inserir na plataforma apenas a informação completa e correta, assim como indicar as razões que justificaram o deferimento ou indeferimento do pedido da AUT.

Em conclusão, apesar da Lista para o ano de 2021 estar ainda em consulta, apresentam-se aqui algumas linhas gerais para que o início do próximo ano se faça de modo tranquilo e sem surpresas em relação a alguns procedimentos. As dúvidas podem ser esclarecidas através do telefone (+351 2105172 13) ou enviando um e-mail (antidopagem@adop.pt).

\section{$16^{\circ}$ Curso de Pós-Graduação em Medicina Desportiva da SPMD (2019/2020)}

\section{Dra. Rita Tomás}

De Outubro de 2019 a Junho de 2020 decorreu o $16^{a}$ Curso de Pós-Graduação em Medicina Desportiva, o qual contou com a participação de 67 alunos. Ao longo de nove meses foram lecionadas 228 horas de aulas aos sábados, por uma equipa de docentes com vasta experiência na área.

O encerramento do curso e último dia de aulas decorreu no dia 27 de Junho, e estas aulas foram abertas a todos os interessados, em formato de open day no Facebook Live. Este foi o segundo ano em que foi utilizado o ensino à distância (e-learning), o que se revelou particularmente importante, dado o contexto que se passou a viver desde Março de 2020.

Os diretores do curso foram a Prof. Doutora Maria João Cascais e o Prof. Doutor Ovídio Costa e o coordenador foi o Dr. Marcos Miranda, os quais prepararam a nova edição, que se iniciou em Outubro de 2020

Aqui ficam os testemunhos de três alunos da última edição:

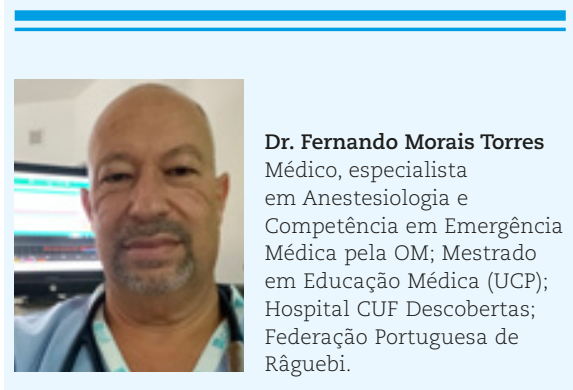

Sendo um médico ligado ao desporto de alto rendimento, sobretudo na área da urgência / emergência em campo e com formação específica e certificada na área, senti necessidade de aumentar os meus conhecimentos em Medicina Desportiva. Foi assim que, ouvidos muitos colegas e amigos do meio desportivo e médico, decidi frequentar o $16^{\circ}$ curso de MD da SPMD. Um curso bastante completo, com bastantes aulas magistrais dadas por alguns dos mestres mais notáveis na área em Portugal. Não exagero se disser que tive algumas das melhores aulas a que assisti até hoje (seja em Portugal, seja em Inglaterra, onde estive ligado ao ensino médico). A motivação foi sempre ampliada à medida que aulas e temas se iam desenvolvendo com inegável consolidação de conhecimentos nesta apaixonante área, num ano deveras complicado. No final, orgulho-me do que aprendi, do que me fez e faz continuar a querer saber mais em prol dos nossos atletas, dos nossos doentes e da população portuguesa que pratica desporto ou atividade física na busca de mais saúde, melhor forma, melhores resultados.

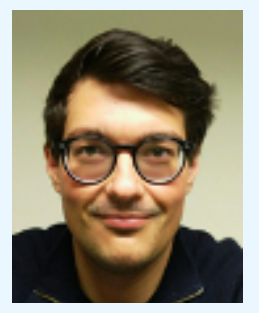

Dr. Daniel Kiessling Médico, Interno de Formação Específica de Medicina Geral e Familiar. ULSAM - USF Vale do Vez

Foi uma experiência enriquecedora que superou as minhas expetativas. O curso teve um programa formativo muito completo que abordou as áreas fulcrais da medicina desportiva, tendo-me permitido adquirir competências importantes para a minha vida profissional e despertado em mim, ainda mais, o interesse por esta área da medicina.

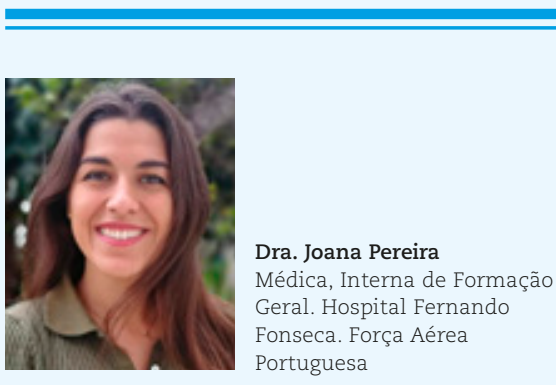

O curso de pós-graduação em medicina desportiva é uma formação muito completa, que foca inúmeros temas importantes e atuais relacionados com a área do desporto de uma forma didática e extremamente interessante. Os módulos estão organizados sequencialmente, 0 que permite que se chegue ao fim do curso com os conhecimentos consolidados da melhor forma. Os formadores e os responsáveis do curso foram sempre extremamente acessíveis e preocupados, estimulando todos os formandos a participar ativamente no decorrer das aulas e retirar o máximo de proveito das mesmas. O curso permite adquirir conhecimentos que vão ser sem dúvida relevantes para quem gosta da área do desporto e pretende ficar ligada a esta de algum modo. É certamente uma boa aposta! 